\title{
Production of hydrogen sulfide from D-cysteine and its therapeutic potential
}

\section{Norihiro Shibuya and Hideo Kimura*}

Department of Molecular Pharmacology, National Institute of Neuroscience, Kodaira, Tokyo, Japan

Edited by:

Sho Kakizawa, Kyoto University, Japan

Reviewed by:

Martin Diener, University Giessen, Germany

Sho Kakizawa, Kyoto University, Japan

*Correspondence:

Hideo Kimura, Department of

Molecular Pharmacology, National

Institute of Neuroscience, 4-1-1

Ogawahigashi, Kodaira, Tokyo

187-8502, Japan

e-mail:kimura@ncnp.go.jp
Accumulating evidence shows that $\mathrm{H}_{2} \mathrm{~S}$ has physiological functions in various tissues and organs. It includes regulation of neuronal activity, vascular tension, a release of insulin, and protection of the heart, kidney, and brain from ischemic insult. $\mathrm{H}_{2} \mathrm{~S}$ is produced by enzymes from L-cysteine; cystathionine $\beta$-synthase, cystathionine $\gamma$-lyase, and 3-mercaptopyruvate sulfurtransferase (3MST) along with cysteine aminotransferase. We recently discovered an additional pathway for the production of $\mathrm{H}_{2} \mathrm{~S}$ from D-cysteine. D-Amino acid oxidase provides 3-mercaptopyruvate for 3MST to produce $\mathrm{H}_{2} \mathrm{~S}$. D-Cysteine protects cerebellar neurons from oxidative stress and attenuates ischemia-reperfusion injury caused in the kidney more effectively than L-cysteine. This review focuses on a novel pathway for the production of $\mathrm{H}_{2} \mathrm{~S}$ and its therapeutic application especially to the renal diseases.

Keywords: hydrogen sulfide, bound sulfane sulfur, L-cysteine, D-cysteine, 3MST, DAO, ischemia-reperfusion injury

\section{INTRODUCTION}

The discovery of endogenous sulfide in the brain urged us to study the function of hydrogen sulfide $\left(\mathrm{H}_{2} \mathrm{~S}\right)$ in the brain (1-3). The recent re-evaluation showed that the endogenous levels of $\mathrm{H}_{2} \mathrm{~S}$ are much lower than those initially evaluated, but this finding confirmed the existence of sulfide in tissues (4-6).

$\mathrm{H}_{2} \mathrm{~S}$ facilitates the induction of hippocampal long-term potentiation, a synaptic model of learning and memory, by enhancing the activity of $\mathrm{N}$-methyl-D-aspartate (NMDA) receptors in neurons, and it induces $\mathrm{Ca}^{2+}$ waves in astrocytes $(7,8)$. It relaxes vascular smooth muscle by activating $\mathrm{K}^{+}$channels, regulates the release of insulin and induces angiogenesis (9-14). It protects neurons from oxidative stress by enhancing the activity of glutathione synthesis, scavenging reactive oxygen species, and suppressing the excessive increase in the intracellular $\mathrm{Ca}^{2+}(15-$ 17). In cardiovascular system, $\mathrm{H}_{2} \mathrm{~S}$ protects cardiomyocytes from ischemia-reperfusion injury by preserving mitochondrial function (18). A similar protective effect was also observed in the kidney (19). $\mathrm{H}_{2} \mathrm{~S}$ is produced from $\mathrm{L}$-cysteine by two pyridoxal $5^{\prime}$ phosphate (PLP)-dependent enzymes, cystathionine $\beta$-synthase (CBS), and cystathionine $\gamma$-lyase (CSE) and PLP-independent 3-mercaptopyruvate sulfurtransferase (3MST) (Figure 1) (7, 9, 20-23). 3MST produces $\mathrm{H}_{2} \mathrm{~S}$ from 3-mercaptopyruvate (3MP), an achiral $\alpha$-keto acid, which is generated by PLP-dependent cysteine aminotransferase (CAT) from L-cysteine and $\alpha$-ketoglutarate $(\alpha$ KG) (24-26). Thioredoxin ( $\operatorname{Trx}$ ) and dihydrolipoic acid (DHLA) are endogenous reducing cofactors that facilitate $\mathrm{H}_{2} \mathrm{~S}$ release from 3MST (23). We recently discovered a novel pathway with D-cysteine as a substrate (27).

\section{PRODUCTION OF H2 $\mathrm{S}$ FROM D-CYSTEINE}

When we examined the production of $\mathrm{H}_{2} \mathrm{~S}$ from brain homogenates, we found that $\mathrm{H}_{2} \mathrm{~S}$ was produced from $\mathrm{D}$-cysteine, originally used as a negative control for L-cysteine (27). $\mathrm{H}_{2} \mathrm{~S}$ producing pathway from $\mathrm{D}$-cysteine is distinct from the pathways involving L-cysteine. There are critical differences between the two pathways; (i) the optimal pH, (ii) the dependency on PLP, and (iii) the stability against the freeze and thaw procedure. The production of $\mathrm{H}_{2} \mathrm{~S}$ from D-cysteine is optimal at $\mathrm{pH} 7.4$, whereas production from $\mathrm{L}$-cysteine is maximal under the alkaline condition. $\mathrm{H}_{2} \mathrm{~S}$ production from $\mathrm{D}$-cysteine is PLP-independent, while that from $\mathrm{L}$-cysteine is PLP-dependent. A single freeze-thaw cycle greatly increases the $\mathrm{H}_{2} \mathrm{~S}$ production from D-cysteine. D-Amino acid oxidase (DAO) that produces $3 \mathrm{MP}$ from $\mathrm{D}$-cysteine is localized to peroxisomes, while $3 \mathrm{MST}$ is mainly found in mitochondria (21, 28). Mitochondria and peroxisomes exchange various metabolites via a specific form of vesicular trafficking, and are usually in close proximity to each other or have physical contact (29). 3MST and DAO can produce $\mathrm{H}_{2} \mathrm{~S}$ by the interaction of both organelles.

\section{LOCALIZATION OF H2S-PRODUCING ENZYMES}

Enzymes producing $\mathrm{H}_{2} \mathrm{~S}$ from L-cysteine are expressed in many tissues $(7,9,17,20,21,23,30,31)$. 3MST is found in neurons in the cerebral cortex, cerebellum, olfactory bulb, pons, and retina, while CBS is preferentially expressed in cerebellar Bergmann glia and in astrocytes throughout the brain $(21,32)$. CSE activity in the brain is only $1 \%$ of the hepatic activity (33). CBS, CSE and 3MST, and CAT are expressed in the liver and kidney (20). Vascular endothelium co-expresses 3MST and CAT (31). The localization of CSE in vascular endothelium is controversial $(31,34)$. Unlike the L-cysteine pathways, the $\mathrm{D}$-cysteine pathway operates predominantly in the cerebellum and the kidney $(27,35)$. In the cerebellum, DAO is expressed in astrocytes, Bergmann glia, and several types of neurons including the Golgi and Purkinje cells $(35,36)$. In the kidney, DAO and 3MST are expressed in the proximal convoluted tubules of the cortex similarly to CBS and CSE (30, 37-39).

\section{REGULATION OF $\mathrm{H}_{2}$ S-PRODUCING ENZYMES BY CA ${ }^{2+}$}

$3 \mathrm{MST} / \mathrm{CAT}$ is regulated by $\mathrm{Ca}^{2+}$; the activity is maximal in the absence of $\mathrm{Ca}^{2+}$ and is completely suppressed at $2.9 \mu \mathrm{M}$ 


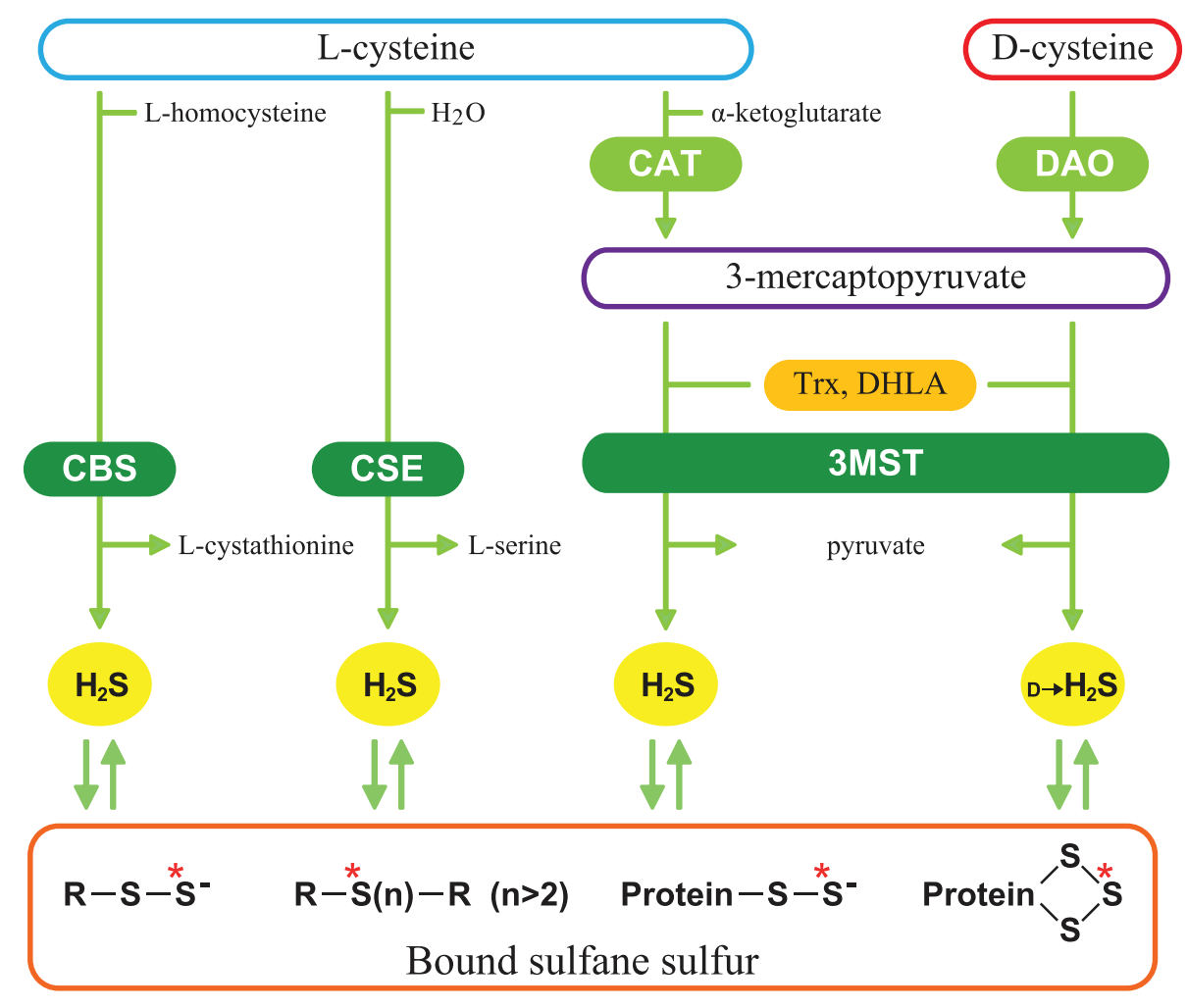

FIGURE 1 | Schematic representation of $\mathrm{H}_{2} \mathrm{~S}$-producing pathways.

Cystathionine $\beta$-synthase (CBS) catalyzes $\beta$-replacement of L-cysteine to produce $\mathrm{H}_{2} \mathrm{~S}$ and L-cystathionine. Cystathionine $\gamma$-lyase (CSE) catalyzes the hydrolysis of L-cysteine. 3-Mercaptopyruvate sulfurtransferase (3MST) produces $\mathrm{H}_{2} \mathrm{~S}$ from 3-mercaptopyruvate (3MP), which is generated by cysteine aminotransferase (CAT) and D-amino acid oxidase (DAO) from
L-cysteine and D-cysteine, respectively. Thioredoxin (Trx) and dihydrolipoic acid (DHLA) are endogenous reducing cofactors that facilitate the release of $\mathrm{H}_{2} \mathrm{~S}$ from $3 \mathrm{MST}$. $\mathrm{H}_{2} \mathrm{~S}$ is stored as bound sulfane sulfur, which is divalent sulfur bound only to other sulfur, such as outer sulfur atoms of persulfides and innerchain atoms of polysulfides. Red asterisks show bound sulfane sulfur.
$\mathrm{Ca}^{2+}$ (17). A similar regulation by $\mathrm{Ca}^{2+}$ is observed in CSE activity (40). $\mathrm{H}_{2} \mathrm{~S}$ is produced by CSE at the steady-state low $\mathrm{Ca}^{2+}$ concentrations and that the production is suppressed by increased $\mathrm{Ca}^{2+}(40)$. Calmodulin is not involved in the regulation of CSE activity. It was previously reported that CSE activity is regulated by $\mathrm{Ca}^{2+} /$ calmodulin in the presence of $1-$ $2 \mathrm{mM} \mathrm{Ca}^{2+}(34)$. Because the intracellular $\mathrm{Ca}^{2+}$ concentrations are between $100 \mathrm{nM}$ and $3 \mu \mathrm{M}$ in endothelium, $\mathrm{Ca}^{2+}$ concentrations used in the previous study are not in the physiological range (41).

\section{SOURCE OF D-CYSTEINE}

Relatively large amounts of D-serine are found in mammalian tissues, and the content of D-serine is up to $15 \sim 30 \%$ of the $\mathrm{L}$-form in the brain $(42,43)$. D-Serine is thought to be produced by PLP-dependent serine racemase, but the Michaelisconstant value of serine racemase is higher than the endogenous levels of L-serine $(42,44-46)$. Although cysteine is structurally similar to serine with an $\mathrm{OH}$ replaced by an $\mathrm{SH}$, serine racemase does not change L-cysteine to D-cysteine (27). Aspartate racemase is homologous to CAT and has an affinity for both aspartate and cysteine $(24,47)$, but does not produce D-cysteine.
A possible source of D-cysteine is absorption from food. LAmino acids are non-enzymatically racemized by heat and alkaline treatment applied during food processing. L-Cysteine is one of the fastest racemizing amino acid, and $21-44 \%$ of $\mathrm{L}$-cysteine is changed to D-cysteine by alkaline treatment $(48,49)$. Although Dcysteine is easily absorbed through the gastrointestinal tract and enters the blood stream (50), D-cysteine is not detected either in the cerebellum or the kidney after the oral administration. Considering the fact that the levels of bound sulfane sulfur, a storage form of $\mathrm{H}_{2} \mathrm{~S}$ (Figure 1), are increased after oral administration of D-cysteine $(5,27), D$-cysteine may be immediately metabolized to produce bound sulfane sulfur in tissues.

\section{CYTOPROTECTIVE EFFECT OF D-CYSTEINE}

The most characteristic feature of the D-cysteine pathway is the greater $\mathrm{H}_{2} \mathrm{~S}$-producing activity in the cerebellum and the kidney compared to the L-cysteine pathway; 7- and 80-fold greater in the cerebellum and the kidney, respectively. Although both Dcysteine and L-cysteine protect cerebellar neurons from hydrogen peroxide-induced oxidative stress (27), D-cysteine protected neurons more greatly than L-cysteine, probably because the transport activity for D-cysteine is greater than that for L-cysteine (51). D-Cysteine may have a potential to improve the developmental 
neuronal diseases in the cerebellum like autism in which oxidative stress may be involved $(52,53)$.

Ischemia-reperfusion injury is observed after cardiovascular surgery, transplantation, or septic as well as hemorrhagic shock. Renal ischemia-reperfusion injury reduces the filtering capacity of the glomerulus and causes acute renal failure (54). Endothelin antagonists, atrial natriuretic peptides, prostaglandins, nitric oxide inhibitors, thyroxine, and human insulin-like growth factor 1 have been studied for the prophylaxis and treatment of acute tubular necrosis without clinical benefit (55-58). We found that the oral administration of $\mathrm{D}$-cysteine attenuates renal ischemiareperfusion injury (27). The structure of glomeruli, which is disintegrated after ischemia-reperfusion, is well preserved by $\mathbf{D}$ cysteine. In contrast, the glomeruli are shrunk and a wide space is observed between glomerulus and the surrounding capsule after ischemia-reperfusion when L-cysteine is applied. D-Cysteine increases the levels of bound sulfane sulfur and protects the renal cortex from the ischemia-reperfusion injury more efficiently than L-cysteine.

\section{D-CYSTEINE: ITS THERAPEUTIC POTENTIAL}

L-Cysteine is metabolized to produce (i) cysteinyl-tRNA by cysteinyl-tRNA synthetase (59), (ii) $\boldsymbol{\gamma}$-glutamylcysteine, a

\section{REFERENCES}

1. Goodwin LR, Francom D, Dieken FP, Taylor JD, Warenycia MW, Reiffenstein RJ, et al. Determination of sulfide in brain tissue by gas dialysis/ion chromatography: postmortem studies and two case reports. J Anal Toxicol (1989) 13:105-9. doi:10.1093/jat/13.2.105

2. Warenycia MW, Goodwin LR, Benishin CG, Reiffenstein RJ, Francom DM, Taylor JD, et al. Acute hydrogen sulfide poisoning. Demonstration of selective uptake of sulfide by the brainstem by measurement of brain sulfide levels. Biochem Pharmacol (1989) 38:973-81. doi:10.1016/00062952(89)90288-8

3. Savage JC, Gould DH. Determination of sulfide in brain tissue and rumen fluid by ion-interaction reversed-phase high-performance liquid chromatography. J Chromatogr (1990) 526:540-5.

4. Furne J, Saeed A, Levitt MD. Whole tissue hydrogen sulfide concentrations are orders of magnitude lower than presently accepted values. Am J Physiol Regul Integr Comp Physiol (2008) 295:R1479-85. doi:10.1152/ajpregu.90566.2008

5. Ishigami M, Hiraki K, Umemura K, Ogasawara Y, Ishii K, Kimura H. A source of hydrogen sulfide and a mechanism of its release in the brain. Antioxid Redox Signal (2009) 11:
205-14. doi:10.1089/ARS.2008. 2132

6. Wintner EA, Deckwerth TL, Langston W, Bengtsson A, Leviten D, Hill P, et al. A monobromobimane-based assay to measure the pharmacokinetic profile of reactive sulphide species in blood. Br J Pharmacol (2010) 160:941-57. doi:10.1111/j.14765381.2010.00704.x

7. Abe K, Kimura H. The possible role of hydrogen sulfide as an endogenous neuromodulator. $J$ Neurosci (1996) 16:1066-71.

8. Nagai Y, Tsugane M, Oka J, Kimura $\mathrm{H}$. Hydrogen sulfide induces calcium waves in astrocytes. FASEB J (2004) 18:557-9.

9. Hosoki R, Matsuki N, Kimura H. The possible role of hydrogen sulfide as an endogenous smooth muscle relaxant in synergy with nitric oxide. Biochem Biophys Res Commun (1997) 237:527-31. doi:10.1006/bbrc.1997.6878

10. Zhao W, Zhang J, Lu Y, Wang R. The vasorelaxant effect of $\mathrm{H}_{2} \mathrm{~S}$ as a novel endogenous gaseous $\mathrm{K}_{\mathrm{ATP}}$ channel opener. EMBO J (2001) 20:6008-16. doi:10.1093/emboj/20.21.6008

11. Yang W, Yang G, Jia X, Wu L, Wang $\mathrm{R}$. Activation of $\mathrm{K}_{\mathrm{ATP}}$ channels by $\mathrm{H}_{2} \mathrm{~S}$ in rat insulin-secreting cells and the underlying mechanisms. J Physiol (2005) 569:519-31. doi:10.1113/jphysiol.2005.097642

12. Kaneko Y, Kimura Y, Kimura H, Niki I. L-Cysteine inhibits

precursor of glutathione, by $\gamma$-glutamylcysteine synthetase, (iii) taurine or pyruvate by cysteine dioxygenase (60), and (iv) propionyl CoA by $\alpha$-keto acid dehydrogenase. Because $\mathrm{D}$-cysteine is not metabolized by these enzymes, D-cysteine must efficiently be utilized to produce $\mathrm{H}_{2} \mathrm{~S}$ in the cerebellum and the kidney.

$\mathrm{L}$-Cysteine is an excitotoxin comparable in potency to other excitatory amino acids and increases the blood pressure and heart rate $(61,62)$. In contrast, D-cysteine neither causes excitotoxic damage to the brain nor disturbs heart function $(63,64)$. Therefore, D-cysteine can be systemically and repeatedly applied with less toxicity compared to L-cysteine. The administration of D-cysteine may provide a new therapeutic approach to protect specific tissues from oxidative stress or ischemia-reperfusion injury through its conversion to $\mathrm{H}_{2} \mathrm{~S}$ via a novel pathway with $3 \mathrm{MST}$ and DAO.

\section{ACKNOWLEDGMENTS}

This work was supported by a grant from the National Institute of Neuroscience, a KAKENHI (23659089) Grant-inAid for Challenging Exploratory Research to Hideo Kimura, a KAKENHI (23700434) Grant-in-Aid for Young Scientists (B), a Health Labour Sciences Research Grant from the Ministry of Health Labour and Welfare to Norihiro Shibuya.

insulin release from the pancreatic beta-cell: possible involvement of metabolic production of hydrogen sulfide, a novel gasotransmitter. Diabetes (2006) 55:1391-7. doi:10.2337/db05-1082

13. Papapetropoulos A, Pyriochou A, Altaany Z, Yang G, Marazioti A Zhou Z, et al. Hydrogen sulfide is an endogenous stimulator of angiogenesis. Proc Natl Acad Sci U S A (2009) 106:21972-7. doi:10.1073/pnas.0908047106

14. Mustafa AK, Sikka G, Gazi SK, Steppan J, Jung SM, Bhunia $\mathrm{AK}$, et al. Hydrogen sulfide as endothelium-derived hyperpolarizing factor sulfhydrates potassium channels. Circ Res (2011) 109:1259-68. doi:10. 1161/CIRCRESAHA.111.240242

15. Kimura Y, Kimura H. Hydrogen sulfide protects neurons from oxidative stress. FASEB J (2004) 18:1165-7.

16. Kimura Y, Goto Y, Kimura H. Hydrogen sulfide increases glutathione production and suppresses oxidative stress in mitochondria. Antioxid Redox Signal (2010) 12:1-13. doi:10.1089/ars.2008.2282

17. Mikami Y, Shibuya N, Kimura $Y$, Nagahara $N$, Yamada $M$, Kimura H. Hydrogen sulfide protects the retina from lightinduced degeneration by the modulation of $\mathrm{Ca}^{2+}$ influx. J Biol Chem (2011) 286:39379-86. doi:10.1074/jbc.M111.298208
18. Elrod JW, Calvert JW, Morrison J, Doeller JE, Kraus DW, Tao L, et al. Hydrogen sulfide attenuates myocardial ischemia-reperfusion injury by preservation of mitochondrial function. Proc Natl Acad Sci U S A (2007) 104:15560-5. doi:10.1073/pnas.0705891104

19. Tripatara P, Patel NS, Collino M, Gallicchio M, Kieswich J, Castiglia S, et al. Generation of endogenous hydrogen sulfide by cystathionine gamma-lyase limits renal ischemia/reperfusion injury and dysfunction. $L a b$ Invest (2008) 88:1038-48. doi:10.1038/labinvest.2008.73

20. Stipanuk MH, Beck PW. Characterization of the enzymic capacity for cysteine desulphhydration in liver and kidney of the rat. Biochem J (1982) 206: 267-77.

21. Shibuya N, Tanaka M, Yoshida M, Ogasawara Y, Togawa T, Ishii $\mathrm{K}$, et al. 3-Mercaptopyruvate sulfurtransferase produces hydrogen sulfide and bound sulfane sulfur in the brain. Antioxid Redox Signal (2009) 11:703-14. doi:10.1089/ARS.2008.2253

22. Singh S, Padovani D, Leslie RA, Chiku T, Banerjee R. Relative contributions of cystathionine beta-synthase and gamma-cystathionase to $\mathrm{H}_{2} \mathrm{~S}$ biogenesis via alternative transsulfuration reactions. $J \mathrm{Biol}$ Chem (2009) 284:22457-66. doi:10.1074/jbc.M109.010868 
23. Mikami Y, Shibuya N, Kimura Y, Nagahara N, Ogasawara Y, Kimura H. Thioredoxin and dihydrolipoic acid are required for 3-mercaptopyruvate sulfurtransferase to produce hydrogen sulfide. Biochem $J$ (2011) 439:479-85. doi:10.1042/ BJ20110841

24. Ubuka $T$, Umemura $S$, Yuasa $S$, Kinuta M, Watanabe K. Purification and characterization of mitochondrial cysteine aminotransferase from rat liver. Physiol Chem Phys (1978) 10:483-500.

25. Akagi R. Purification and characterization of cysteine aminotransferase from rat liver cytosol. Acta Med Okayama (1982) 36:187-97.

26. Cooper AJ. Biochemistry of sulfur-containing amino acids. Annu Rev Biochem (1983) 52:187-222. doi:10.1146/annurev. bi.52.070183.001155

27. Shibuya N, Koike S, Tanaka M, Ishigami-Yuasa M, Kimura Y, Ogasawara Y, et al. A novel pathway for the production of hydrogen sulfide from Dcysteine in mammalian cells. Nat Commun (2013) 4:1366. doi:10.1038/ncomms2371

28. Gould SJ, Keller GA, Subramani S. Identification of peroxisomal targeting signals located at the carboxy terminus of four peroxisomal proteins. $J$ Cell Biol (1988) 107:897-905. doi:10.1083/jcb.107.3.897

29. Schumann U, Subramani S. Special delivery from mitochondria to peroxisomes. Trends Cell Biol (2008) 18:253-6. doi:10.1016/j.tcb.2008.04.002

30. Ishii I, Akahoshi N, Yu XN, Kobayashi Y, Namekata K, Komaki $\mathrm{G}$, et al. Murine cystathionine gamma-lyase: complete cDNA and genomic sequences, promoter activity, tissue distribution and developmental expression. Biochem J (2004) 381:11323. doi:10.1042/BJ20040243

31. Shibuya N, Mikami Y, Kimura $\mathrm{Y}$, Nagahara $\mathrm{N}$, Kimura $\mathrm{H}$. Vascular endothelium expresses 3-mercaptopyruvate sulfurtransferase and produces hydrogen sulfide. J Biochem (2009) 146:623-6. doi:10.1093/jb/mvp111

32. Enokido Y, Suzuki E, Iwasawa $\mathrm{K}$, Namekata $\mathrm{K}$, Okazawa $\mathrm{H}$, Kimura H. Cystathionine betasynthase, a key enzyme for homocysteine metabolism, is preferentially expressed in the radial glia/astrocyte lineage of developing mouse CNS. FASEB J (2005) 19:1854-6.

33. Diwakar L, Ravindranath V. Inhibition of cystathionine-gammalyase leads to loss of glutathione and aggravation of mitochondrial dysfunction mediated by excitatory amino acid in the CNS. Neurochem Int (2007) 50:418-26. doi:10.1016/j.neuint.2006.09.014

34. Yang $G$, Wu L, Jiang $B$, Yang W, Qi J, Cao K, et al. $\mathrm{H}_{2} \mathrm{~S}$ as a physiologic vasorelaxant: hypertension in mice with deletion of cystathionine gammalyase. Science (2008) 322:587-90. doi:10.1126/science.1162667

35. Mitchell J, Paul P, Chen HJ, Morris A, Payling M, Falchi M, et al. Familial amyotrophic lateral sclerosis is associated with a mutation in D-amino acid oxidase. Proc Natl Acad Sci U S A (2010) 107:755661. doi:10.1073/pnas.0914128107

36. Moreno S, Nardacci R, Cimini A, Cerù MP. Immunocytochemical localization of $\mathrm{D}$-amino acid oxidase in rat brain. $J$ Neurocytol (1999) 28:169-85. doi:10.1023/A:1007064504007

37. Perotti ME, Gavazzi E, Trussardo L, Malgaretti N, Curti B. Immunoelectron microscopic localization of D-amino acid oxidase in rat kidney and liver. Histochem J (1987) 19:157-69. doi:10.1007/BF01695140

38. House JD, Brosnan ME, Brosnan JT. Characterization of homocysteine metabolism in the rat kidney. Biochem J (1997) 328:287-92.

39. Nagahara N, Ito $\mathrm{T}$, Kitamura $\mathrm{H}$, Nishino T. Tissue and subcellular distribution of mercaptopyruvate sulfurtransferase in the rat: confocal laser fluorescence and immunoelectron microscopic studies combined with biochemical analysis. Histochem Cell Biol (1998) 110:24350. doi:10.1007/s004180050286

40. Mikami Y, Shibuya N, Ogasawara Y, Kimura H. Hydrogen sulfide is produced by cystathionine $\gamma$-lyase at the steady-state low intracellular $\mathrm{Ca}^{2+}$ concentrations. Biochem Biophys Res Commun (2013) 431:131-5. doi:10.1016/j.bbrc.2013.01.010

41. Rutter GA, Rizzuto R. Regulation of mitochondrial metabolism by ER $\mathrm{Ca} 2+$ release: an intimate connection. Trends Biochem Sci (2000) 25:215-21. doi:10.1016/S09680004(00)01585-1

42. Mothet JP, Parent AT, Wolosker $\mathrm{H}$, Brady RO Jr, Linden DJ,
Ferris CD, et al. D-serine is an endogenous ligand for the glycine site of the N-methyl-Daspartate receptor. Proc Natl Acad Sci U S A (2000) 97:4926-31. doi:10.1073/pnas.97.9.4926

43. Hamase K, Konno R, Morikawa A, Zaitsu K. Sensitive determination of D-amino acids in mammals and the effect of D-amino-acid oxidase activity on their amounts. Biol Pharm Bull (2005) 28:1578-84. doi:10.1248/bpb.28.1578

44. Wolosker H, Sheth KN, Takahashi M, Mothet JP, Brady RO Jr, Ferris $\mathrm{CD}$, et al. Purification of serine racemase: biosynthesis of the neuromodulator D-serine. Proc Nat Acad Sci U S A (1999) 96:721-5. doi:10.1073/pnas.96.2.721

45. Strísovský K, Jirásková J, Barinka C, Majer P, Rojas C, Slusher BS, et al. Mouse brain serine racemase catalyzes specific elimination of L-serine to pyruvate. FEBS Lett (2003) 535:44-8. doi:10.1016/S00145793(02)03855-3

46. Miyoshi Y, Konno R, Sasabe J, Ueno K, Tojo Y, Mita M, et al. Alteration of intrinsic amounts of $\mathrm{D}$-serine in the mice lacking serine racemase and $\mathrm{D}$-amino acid oxidase. Amino Acids (2012) 43:1919-31. doi:10.1007/s00726012-1398-4

47. Kim PM, Duan X, Huang AS, Liu CY, Ming GL, Song H, et al. Aspartate racemase, generating neuronal $\mathrm{D}$-aspartate, regulates adult neurogenesis. Proc Nat Acad Sci U S A (2010) 107:3175-9. doi:10.1073/pnas.0914706107

48. Liardon R, Ledermann S. Racemization kinetics of free and protein-bound amino acids under moderate alkaline treatment. $J$ Agric Food Chem (1986) 34:55765. doi:10.1021/jf00069a047

49. Friedman M. Origin, microbiology, nutrition, and pharmacology of D-amino acids. Chem Biodivers (2010) 7:1491-530. doi:10.1002/cbdv.200900225

50. Krijgsheld KR, Glazenburg EJ, Scholtens E, Mulder GJ. The oxidation of $\mathrm{L}^{-}$and D-cysteine to inorganic sulfate and taurine in the rat. Biochim Biophys Acta (1981) 677:7-12. doi:10.1016/03044165(81)90139-2

51. Fukasawa Y, Segawa H, Kim JY, Chairoungdua A, Kim DK, Matsuo $\mathrm{H}$, et al. Identification and characterization of a $\mathrm{Na}^{+}$independent neutral amino acid transporter that associates with the $4 \mathrm{~F} 2$ heavy chain and exhibits substrate selectivity for small neutral D- and L-amino acids. J Biol Chem (2000) 275:9690-8. doi:10.1074/jbc.275.13.9690

52. Fonnum F, Lock EA. Cerebellum as a target for toxic substances. Toxicol Lett (2000) 112113:9-16. doi:10.1016/S03784274(99)00246-5

53. Sajdel-Sulkowska EM, Xu M, Koibuchi N. Increase in cerebellar neurotrophin-3 and oxidative stress markers in autism. Cerebellum (2009) 8:366-72. doi:10.1007/s12311-009-0105-9

54. Thadhani R, Pascual M, Bonventre JV. Acute renal failure. $N$ Engl J Med (1996) 334: 1448-60. doi:10.1056/NEJM1996 05303342207

55. Allgren RL, Marbury TC, Rahman SN, Weisberg LS, Fenves AZ, Lafayette RA, et al. Anaritide in acute tubular necrosis. Auriculin Anaritide Acute Renal Failure Study Group. $N$ Engl J Med (1997) 336:828-34. doi:10. 1056/NEJM199703203361203

56. Hirschberg R, Kopple J, Lipsett P, Benjamin E, Minei J, Albertson $\mathrm{T}$, et al. Multicenter clinical trial of recombinant human insulin-like growth factor I in patients with acute renal failure. Kidney Int (1999) 55:2423-32. doi:10.1046/j.15231755.1999.00463.x

57. Acker CG, Singh AR, Flick RP, Bernardini J, Greenberg A, Johnson JP. A trial of thyroxine in acute renal failure. Kidney Int (2000) 57:293-8. doi:10.1046/j.1523 1755.2000.00827.x

58. Wang A, Holcslaw T, Bashore TM, Freed MI, Miller D, Rudnick MR, et al. Exacerbation of radiocontrast nephrotoxicity by endothelin receptor antagonism. Kidney Int (2000) 57:1675-80. doi:10.1046/j.15231755.2000.00012.x

59. Ibba M, Söll D. Quality control mechanisms during translation. Science (1999) 286:1893-7. doi:10.1126/science.286.5446.1893

60. Yamaguchi K, Hosokawa Y, Kohashi N, Kori Y, Sakakibara S, Ueda I. Rat liver cysteine dioxygenase (cysteine oxidase). Further purification, characterization, and analysis of the activation and inactivation. J Biochem (1978) 83:479-91.

61. Olney JW, Zorumski C, Price MT, Labruyere J. L-cysteine, a bicarbonate-sensitive endogenous excitotoxin. Science (1990) 
248:596-9. doi:10.1126/science. 2185543

62. Janáky R, Varga V, Hermann A, Saransaari P, Oja SS. Mechanisms of L-cysteine neurotoxicity. Neurochem Res (2000) 25:1397-405. doi:10.1023/A:1007616817499

63. Misra CH. Is a certain amount of cysteine prerequisite to produce brain damage in neonatal rats? Neurochem Res (1989) 14:253-7. doi:10.1007/BF00971320
64. Takemoto Y. Pressor response to $\mathrm{L}$-cysteine injected into the cisterna magna of conscious rats involves recruitment of hypothalamic vasopressinergic neurons. Amino Acids (2012) 44:1053-60. doi:10.1007/s00726-012-1440-6

Conflict of Interest Statement: The authors declare that the research was conducted in the absence of any commercial or financial relationships that could be construed as a potential conflict of interest.

Received: 28 May 2013; paper pending published: 26 June 2013; accepted: 01 July 2013; published online: 16 July 2013. Citation: Shibuya $N$ and Kimura $H$ (2013) Production of hydrogen sulfide from D-cysteine and its therapeutic potential. Front. Endocrinol. 4:87. doi:10.3389/fendo.2013.00087
This article was submitted to Frontiers in Experimental Endocrinology, a specialty of Frontiers in Endocrinology.

Copyright (C) 2013 Shibuya and Kimura.

This is an open-access article distributed under the terms of the Creative Commons Attribution License, which permits use, distribution and reproduction in other forums, provided the original authors and source are credited and subject to any copyright notices concerning any third-party graphics etc. 